\title{
Assessment of Substance Use and Risky Sexual Behaviour Among Public College Students in Bonga Town, Southwest Ethiopia
}

\author{
Agegnehu Alemu ${ }^{1}$, MuluegtaShegaze ${ }^{1,3, *}$, TeshomeGobena ${ }^{1,2}$, HailayAbraha ${ }^{1,2}$, \\ Gebremaryam Temesgen $^{4}$, Yohannes Markos ${ }^{1,2}$ \\ ${ }^{1}$ Department of Biomedical Sciences, Jimma University, Jimma, Ethiopia \\ ${ }^{2}$ Department of Epidemiology Sciences, Jimma University, Jimma, Ethiopia \\ ${ }^{3}$ Department of Nursing, College of Medicine and Health Sciences, Arba Minch University, Arba Minch, Ethiopia \\ ${ }^{4}$ Department of Midwifery, College of Medicine and Health Sciences, Arba Minch University, Arba Minch, Ethiopia
}

Email address:

aagegnewalemu@ymail.com. (A. Alemu),mulsheg@yahoo.com (M. Shegaze), teshomeglemu@yahoo.com. (T. Gobena), hailushepi@gmail.com. (H. Aberaha)

\section{To cite this article:}

Agegnehu Alemu, Muluegta Shegaze, Teshome Gobena, Hailay Abraha, Gebremaryam Temesgen, Yohannes Markos. Assessment of Substance Use and Risky Sexual Behaviour Among Public College Students in Bonga Town, Southwest Ethiopia. American Journal of Biomedical and Life Sciences. Vol. 3, No. 5, 2015, pp. 91-97. doi: 10.11648/j.ajbls.20150305.11

\begin{abstract}
Background: Substance use and problems arising from it are increasing all over the world, and currently together with HIV/AIDS epidemic, become one of the most threatening and challenging social and public health problems. College students are more vulnerable to wider sexual and reproductive health and HIV/AIDS problems due to new environment with poor protection, age and the need to explore life, peer pressure and absence of proactive programs. Objective: The main objective of this study was to assess the magnitude of risky sexual behavior and its association with substance use among Bonga town public college students. Methods: A cross-sectional study was conducted among 396 Bonga town public college students from March 2014 to April 2014 using stratified sampling technique and a self-administered questionnaire was used. Descriptive statistics was used to describe the study population, prevalence, and to check the missing values, outliers, and inconsistencies. Logistic regressions to determine independent predictors of risky sexual behaviors and the p- value of 0.05 was used as cut off point for the presence of statistical significance. Results: Among 396 participants $72.7 \%$ reported having used at least one substance in their life time. Commonly used substances were: alcohol $(51.3 \%)$ followed by khat $(15.4 \%)$, cigarette (3.6\%) and other illicit substances (2.5\%). From total respondents $38.1 \%$ admitted having sexual experience. Among sexually experienced males $4.6 \%$ have had sexual intercourse with commercial sex workers and $4.6 \%$ had sexual intercourse with more than one person. Condom use rate was $64.9 \%$ but, its consistency was $58.3 \%$. Sex, educational status, income and ever use of khat were statistically associated with risky sexual behavior with AOR $(95 \% \mathrm{CI})$ of $4.5(1.7,12), 4.7(1.6,12.9), 3.7$ $(1.4,10), 2.5(1.1,6.5)$ respectively. Conclusion: The prevalence of substance use among Bonga college students was high. The study also showed that many of the students who were sexually active engaged in unsafe and risky sexual practices. Awareness rising about safer sex and consequences of substance use for college students is necessary measure that should be taken.
\end{abstract}

Keywords: Risky Sezxual Behavior, Reproductive Health, Substance Use, College Students, Ethiopia

\section{Introduction}

The local definition of youth as it is a cultural phenomenon differs among societies and culture. However, United Nation (UN) defines youth as those in the age group between 15 to 24 years [1], which is having the same definition as it is used by the Ethiopian Social Security and Development Policy
(ESSDP). This segment of the population constitutes more than one billion of the world population, with four out of five living in the developing countries [1,2]. In Ethiopia, according to the Ministry of Health as cited in Govindasamy et al., youth represent a significant proportion of the society. Currently, it is estimated that young people between ages 10-24 constitute more than one third of the total population which is roughly more than 21 million [2]. 
World Health Organization reported in 2011 that unsafe sex was second among the top ten risk factors in the global burden of all diseases caused globally. There is little information on the incidence and prevalence of STIs in Ethiopia. The prevalence of syphilis is thought to be about $2.7 \%$ [3]. There is no actual information or estimate on other STIs in Ethiopia. This is because reports often under-represent the true number of people infected with STIs. Major contributing factor is that people with STIs who have minor or no symptoms do not seek treatment at public health facilities. They usually tend to take self-prescribed drugs or go to private pharmacies to buy treatment without consulting trained health workers [4, 5].

According to The Joint United Nations Program on HIV/AIDS (UNAIDS), in 2009 young people aged 15-24 years accounted for $42 \%$ of new HIV infections in people aged 15 and older and nearly $80 \%$ of this live in sub-Saharan Africa [4].Ethiopia is one of the sub-Saharan countries worst affected by the HIV/AIDS pandemic. According to the Ministry of Health of Ethiopia report in 2008, approximately 1,345,970 people were living with HIV. In 2008 , the national adult HIV prevalence was estimated to be $2.1 \%$ [5].

Physical sexual arousal (e.g., erection of the penis in the male, swelling of the clitoris and genital engorgement in the female) involves increased blood flow to the genital area. Anything that alters the cardio-vascular system's ability to pump blood to the genitals can slow down or reduce the intensity of this genital response. Alcohol consumption increases sexual desire and arousal, although it lowers physiological arousal [6]. Effects of khat on the chewer include increased levels of energy, increased self-esteem, euphoria, increased libido, excitement, and increased proclivity for social interaction [7]. Cigarette smoking has been shown to reduce sexual arousal by impeding the circulatory system's delivery of oxygenated blood throughout the body [8].

Demographic Health Surveys (DHS) in many of the developing countries have shown that today, boys and girls experience puberty at younger ages than the previous generations; most of these changes are attributed to better health and nutrition [9].

As a result, the transition period from childhood to adulthood increases, rapid reproductive maturity will be marked, which could involve them in early and non-marital sexual activity, most of it being unsafe, with the reluctance to use contraceptive and exposing them to all its consequences, such as, unwanted pregnancy, abortion and Sexually Transmitted Diseases (STD) including HIV/AIDS.As far as youths are exposed to high risk activities /behavior like alcohol drinking and addictive substances like chat chewing and shisha smoking, it is obviously associated with reproductive health risks [10].

Based on the study conducted in 2008 in North East Ethiopia by Fekadu Mazengia and Alemayehu Worku about half, $51.3 \%$ of the youths have ever had sex. The median age at sexual debut was 16 years for rural and 17 years for urban. Multivariate analysis showed that being female by gender, chewing Khat, drinking alcohol, watching pornographic materials at age $<18$ yearsand being less connected with parents were associated with early sexual initiation [11].

Risk sexual behaviors, including early sexual debut, unprotected sexual intercourse, and multiple sexual partners, occur in a broader context. The intensity of involvement in sexual risk behavior ranges from no sexual relationship to unprotected sexual intercourse with multiple partners and prostitution. Sexual risk behaviors often cluster with other risk behaviors including substance use. Adolescents who engage in sexual intercourse at young ages are at higher risk for outcomes that can compromise their health. Sexually active teens who exhibit few positive or prosaically behaviors, such as involvement in organized actions at school or in the community, are at higher risk for outcomes such as early sexual activity and pregnancy during their teenage years [12]. According to Ethiopian Health and Demographic survey risky sexual behaviors is having multiple sexual partners, inconsistent condom use and commencing sex with commercial sex worker [4, 5].Risky sexual behaviors can result in sexually transmitted diseases and unintended pregnancies. Colleges are institutions of higher learning providing education to undergraduates and award diplomas and degrees in specific academic fields. Students of higher learning institutions are people with multiple socio-cultural grounds begin autonomous life at younger age for first time. Study findings reveal most of students of higher education rush to range of maladaptive high-risk extracurricular activities like alcohol use, substance and sexual abuse [13].

Substance use has been documented as a contributing factor to sexual risk-taking, whereby substance use impairs individual judgment and decision-making and increases a one's risk for a sexually transmitted infection (STI). Several major observations were emerged from a study done in America on adolescent students. It showed that both casual and chronic substance users are more likely to engage in high-risk behaviors such as unprotected sex when they are under the influence of drugs or alcohol. This study further revealed that substance use was significantly associated with unprotected sexual behaviors [14].

According to the work of Lori-Ann, Edward A. in South Africa in 2009aboutTransitions to Substance Use and Sexual Intercourse Among South African High School Students result showed that students in the sample were most likely to initiate substance use as their first risk behavior, before moving on to sexual intercourse at a later time point. The potential explanations for this sequencing fall into two categories. The initiation of substance use may be a direct or indirect cause of sexual initiation. Alternatively, substance use may precede sex because of an outside factor or process [15].

A study done on cigarette smoking and khat chewing among college students in North West Ethiopia revealed $13.1 \%$ lifetime prevalence of cigarette smoking and $26.7 \%$ life time prevalence rate of khat chewing. In the study, prevalence of cigarette smoking was found to be $8.1 \%$. Forty six $(31.7 \%)$ of the life time smokers and $134(45.6 \%)$ of the life time chewers started smoking and chewing while they were senior secondary school students [16]. 
Another study done on substance use and risky sexual behavior among Haromaya University students reveal that use of khat, alcohol and cigarette was significantly and independently associated with risky sexual activities [17].

The study done on substance use and risky sexual behavior in Southern Ethiopia, Hossana Health Science College reveal that Practicing sex with multiple partners, inconsistent condom use and commencing sex with female commercial sex workers, which were highly risky sexual behaviors for HIV infection transmission among study participants, were commonly practiced [18-22].

The rapid economic, social, and cultural transitions that most countries in sub-Saharan Africa are now experiencing have created a breeding ground for increased and socially disruptive use of alcohol and drugs. Given the high prevalence of human immune deficiency virus/acquired immune deficiency syndrome (HIV/AIDS) in the region and the increasing number of adolescents infected with HIV, an understanding of the role of substance use plays in the spread of HIV/AIDS is crucial to prevention efforts of the disease among adolescent population [23].

Students at higher institutions are considered to be fully aware of HIV /AIDS risks/preventive mechanisms and reproductive health $(\mathrm{RH})$ issues. As a result, they are neglected of HIV/AIDS and RH interventions. However, on arrival at college, many students encounter new independence and freedom life and are at risk of HIV infection [24].

The aim of this study was to assess the magnitude of risky sexual behavior (no condom use, having sexual intercourse at age $<18$, sexual intercourse with multiple partners and sex with commercial sex workers) and its association with substance use (alcohol, khat, cigarette and illicit drugs) among Bonga public college students.

\section{Materials and Methods}

\subsection{Study Setting, Study Design and Sampling}

A cross-sectional study was conducted in SNNPR State, Kafa Zone, Bonga town on two public colleges' students. Data were collected in March 2014. Sample size was determined using single population proportion formula for cross-sectional study. Using the above formula, sample size for the single population proportion was 379 and after adding $10 \%$ non response rate (contingency) the total sample size became 417. In sampling procedure, first students were divided into TTC and TVET colleges. Then, they were further stratified based on year of study. Finally, stratified random sampling technique was applied to select individuals in each year of study from the list of students name in their respective batch. Students for each year of study were allocated proportionally to their class size based on the inclusion criteria and were selected randomly using computer generated method. Data were collected by using structured self-administered questionnaire prepared in English and translated to Amharic and retranslated to English to ensure its consistency.

\subsection{Statistical Analysis}

Data were checked for completeness before entry and then entered and cleaned using Epi-Info version 3.1. SPSS version 16 was used for statistical analysis. Bivariate analysis was used to know the crude association between independent variable with outcome variable. Multi-co linearity was checked by VIF and goodness of fit of the model was checked via Hosmer and Lemeshow's test. All variables significance at $p$-value $<0.25$ on bivariate analysis was candidate for multi-variable logistic regression to know independent predictors of outcome variables. Odds ratio with $95 \%$ confidence interval was computed to assess the level of association and statistical significance.

\subsection{Ethical Consideration}

Ethical clearance was obtained from Ethical Committee of Jimma University, College of Public Health and Medical Sciences. Permission will be sought from Bonga College of Teachers Education and Bonga TVET College.

\section{Results}

\subsection{Socio-Demographic Characteristics}

Table 1. Respondent characteristics by socio demographic variable.

\begin{tabular}{|c|c|c|c|}
\hline Variables & Level & $\mathrm{N}=396$ & $\%$ \\
\hline \multirow{3}{*}{ Age } & $15-18$ & 73 & 18.4 \\
\hline & $19-24$ & 315 & 79.5 \\
\hline & $>24$ & 8 & 2.0 \\
\hline \multirow{2}{*}{ Sex } & male & 271 & 68.4 \\
\hline & female & 125 & 31.6 \\
\hline \multirow{3}{*}{ Educational status } & First year and level1 & 139 & 35.1 \\
\hline & Second year and level 2 & 143 & 36.1 \\
\hline & 3rdyear and level 3 and 4 & 114 & 28.8 \\
\hline \multirow{5}{*}{ Religion } & Orthodox & 253 & 63.9 \\
\hline & Muslim & 19 & 4.8 \\
\hline & Protestant & 115 & 29.0 \\
\hline & Catholic & 8 & 2.0 \\
\hline & Others & 1 & 0.3 \\
\hline \multirow{2}{*}{ Marital status } & Never married & 351 & 88.6 \\
\hline & Ever married & 45 & 11.4 \\
\hline \multirow{6}{*}{ Ethnicity } & Kafa & 260 & 65.7 \\
\hline & Sheka & 33 & 8.3 \\
\hline & Bench & 40 & 10.1 \\
\hline & Amhara & 28 & 7.1 \\
\hline & Oromo & 16 & 4.0 \\
\hline & Others & 19 & 4.8 \\
\hline \multirow{2}{*}{ Place lived before } & Urban & 179 & 45.2 \\
\hline & Rural & 217 & 54.8 \\
\hline \multirow{2}{*}{ School type } & Government school & 395 & 99.7 \\
\hline & Privateschool & 1 & 0.3 \\
\hline \multirow{3}{*}{ Income } & $<100$ & 204 & 51.5 \\
\hline & $100-299$ & 129 & 32.6 \\
\hline & $>=300$ & 63 & 15.9 \\
\hline
\end{tabular}

Out of the total 417 students participated in the study, questionnaires from 396 respondents were considered for analysis making the response rate $95 \%$. Of the total 396 respondents, most $315(79.5 \%)$ were youths, 271 (68.4\%) were males, 139 (35.1\%) were first year students who stayed one year in the town. Majority of the study participants, $63.9 \%$ 
(253) were followers of orthodox religion followed by protestants $115(29 \%)$. About 88.6\% were never married including single and cohabitating while the remaining 45 (11.4) were ever married. Considering the ethnicity of the study participants majority are Kafa $260(65.7 \%)$ followed by Bench $40(10.1 \%)$ and Sheka $33(8.3 \%)$. In looking at income of respondents $51.5 \%$ (204) of the students reported a monthly pocket money of $<100$ and the remaining $32.8 \%$ (130) and $15.9 \%(63)$ of the students reported a monthly pocket money of 100 to 299 birr and above 300 respectively (Table 1. annex).

\subsection{Prevalence of Substance Use Behavior}

The study revealed that $61(15.4 \%)$ of the students chew khat at least once in their lifetime and $11.4 \%$ reported that they were current khat chewers (in the last 3 months). The prevalence among males $54(19.9 \%)$ was higher compared to females $7(5.6 \%)$. The respondents were further asked their chewing pattern. The response indicated that about $11.1 \%$ chew khat occasionally (2-3 times per week), $4.8 \%$ of them used to chew khat but not now and $0.3 \%$ of them claimed chewing khat always (everyday).Concerning alcohol drinking habits, $203(51.3 \%)$ reported that they drank alcohol at least once in their lifetime while $178(44.9 \%)$ said that they drank alcohol in the last three months. Among alcohol users, the majority (50.5\%) were using alcoholic drinks occasionally. (Tables 2)

Respondents used cigarette at least once in their life time were $14(3.6 \%)$. The current prevalence of cigarette smoking was $1.5 \%$ and all of the smokers were occasional smokers. Furthermore, $10(2.5 \%)$ of the study participants used illicit substances like hashish at least once, with all of them being occasional users. Among the participants, 288 (72.7\%) reported having used at least one substance in their lifetime. From those who used at least one substance in their life time, $196(68 \%)$ started using the drugs before joining the college while 92 (32\%) started after joining college.

Table 2. Prevalence of ever and currently substance use among bonga public college students, 2014.

\begin{tabular}{lll}
\hline Type of substance & $(\mathbf{N = 3 9 6 )}$ & Percent \\
\hline Substances ever use & & \\
Khat & 61 & $15.4 \%$ \\
Alcoholic & 203 & $51.3 \%$ \\
Cigarette & 14 & $3.6 \%$ \\
Illicit drugs & 10 & $2.5 \%$ \\
Substance currently use & & \\
Khat & 45 & 11.4 \\
Alcohol & 178 & 44.9 \\
Cigarette & 6 & 1.5 \\
Illicit drugs & 6 & 1.5 \\
\hline
\end{tabular}

\subsection{Reason for Substance Use}

Different reasons were mentioned by students for the use of drugs. The reasons mentioned for khat ever use were: To increase work performance $25(40.1 \%)$, due to peer influence $(19.4 \%)$, to be sociable $(9.7 \%)$, to get relief from tension $(8.1 \%)$, to get acceptance by others $(8.1 \%)$, to get personal pleasure during sexual intercourse $(6.4 \%)$, and other reasons
(4.8\%). Among 203 students who reported taking alcohol, $34.7 \%$ used alcohol to get personal pleasure, $17.6 \%$ took it due to peer influence, $11.1 \%$ to get relief from tension, $9 \%$ to be sociable and $19 \%$ for other reasons. Reasons for cigarette smoking were: to get relief from tension $(28.6 \%)$, peer influence $(28.6 \%)$, to get personal pleasure $(21.4 \%)$, to stay awoke $(14.3 \%)$ and to get acceptance by others (7.1\%).Reasons for illicit drug use were: to get relief from tension $(37.5 \%)$, to increase pleasure during sexual intercourse $(37.5 \%)$, to stay awoke $(12.5 \%)$ and to work hard $(12.5 \%)$.

Prevalence of cigarette smoking and illicit drug use were low. This may be due to small sample size and fear of respondents to give genuine response for the given questions due to illegality of illicit drug use.

Table 3. Reason for substance use, bonga college students, 2014.

\begin{tabular}{|c|c|c|c|}
\hline Variables & Level & $\mathbf{N}$ & $\%$ \\
\hline \multirow{7}{*}{$\begin{array}{l}\text { Reason for chewing } \\
\text { chat }(\mathrm{N}=61)\end{array}$} & To work /study hard & 25 & 40.1 \\
\hline & To get relief from tension & 5 & 8.2 \\
\hline & To be alert & 4 & 6.5 \\
\hline & To get acceptance from others & 5 & 8.2 \\
\hline & To be sociable & 6 & 9.8 \\
\hline & $\begin{array}{l}\text { To get pleasure during sexual } \\
\text { intercourse }\end{array}$ & 3 & 4.9 \\
\hline & Due to peer influence & 13 & 21.3 \\
\hline \multirow{8}{*}{$\begin{array}{l}\text { Reason for drinking } \\
(\mathrm{N}=203)\end{array}$} & To work/ study hard & 17 & 8.4 \\
\hline & To get relief from tension & 22 & 10.8 \\
\hline & To be alert & 16 & 7.9 \\
\hline & To get acceptance from others & 15 & 7.4 \\
\hline & To be sociable & 18 & 8.8 \\
\hline & To get personal pleasure & 69 & 34.0 \\
\hline & $\begin{array}{l}\text { To get pleasure during sexual } \\
\text { intercourse }\end{array}$ & 5 & 2.4 \\
\hline & Due to peer influence & 35 & 17.2 \\
\hline \multirow{4}{*}{$\begin{array}{l}\text { Reason for smoking } \\
(\mathrm{N}=14)\end{array}$} & To get relief from tension & 4 & 28.6 \\
\hline & To be alert & 2 & 14.3 \\
\hline & To get personal pleasure & 3 & 21.4 \\
\hline & Due to peer influence & 4 & 28.6 \\
\hline \multirow{2}{*}{$\begin{array}{l}\text { Reason for using of } \\
\text { illicit drugs }(\mathrm{N}=10)\end{array}$} & To get relief from tension & 3 & 30 \\
\hline & $\begin{array}{l}\text { To get pleasure during sexual } \\
\text { intercourse }\end{array}$ & 7 & 70 \\
\hline
\end{tabular}

\subsection{Sexual Behaviors of Respondents}

Out of the total respondents, 151 (38.1\%) of students had sexual experience. Of the 151 sexually active students, 103 $(68.2 \%)$ were males and $48(31.8 \%)$ were females. A total of $84(55.6 \%)$ participants had their first sex before joining the college. The main reasons for initiating sex were related to personal interest or curiosity $57(37.7 \%)$, promising word from partner for marriage $56(37.2 \%)$, peer pressure 18 $(11.9 \%)$, marriage $15(9.9 \%)$ and other reasons such as forced sex and for passing examination $5(3.3 \%)$. Majority of the sexually experienced students $124(82.1 \%)$ had their first sex with their girlfriends/ boyfriends, $21(13.9 \%)$ with their spouse, $3(2.0 \%)$ with stranger and $4(2.5 \%)$ of the respondents had their first sex with their teachers.

From 151 sexually active students, 83 (54.96\%) had at least one of the risky sexual behaviors. i.e. 7 (4.6\%) had sexual intercourse with multiple sexual partners in the last 
three months, $7(4.6 \%)$ of males had sex with commercial sex workers, $53(35.1 \%)$ respondents do not use condom, 10 (6.6\%) use condom inconsistently and 57 (37.7\%) had started sexual intercourse before the age of 18 years and 51 of them are victims of the above risky sexual behaviors. The most common reason cited for not using condom was in love with partner $(29.8 \%)$, followed by trust of partner $(19.2 \%)$ and no reason (12.5\%). Among the sexually active students who were asked if they had symptoms of STI (genital discharge or ulceration), $21(13.9 \%)$ responded that they had the symptoms. From these students that had these symptoms, only 3 sought medical care for the symptom they had and 18 of them ignored it. Regarding use of contraceptive methods last time they had sexual intercourse, majority, 98 (64.9\%) had used and the remaining $53(35.1 \%)$ had not use any. Pertaining the type of contraceptive methods, 35(23.2\%) used condom, 37 (24.5\%) used pills, 26 (17.2\%) used DepoProvera. Among 48 sexually active female students, 18 $(37.5 \%)$ had once been pregnant and 4 students became pregnant twice. Concerning the outcome of pregnancy, 15 $(68.2 \%)$ ended in abortion whilst the rest 7 (31.8\%) gave birth.

\subsection{Independent Predictors of Risky Sexual Behavior}

In bivariate analysis different variables including year of study, marital status, original place and income were associated with risky sexual behavior.

After controlling for the effects of potentially confounding variables using multivariate logistic regression sex, educational status, income and ever use of khat were found to be significantly associated with risky sexual behavior. The odds of performing risky sexual behavior among females were about four and half times higher than that of males ( $\mathrm{AOR}=4.5,95 \% \mathrm{CI}=1.7,12)$. There was also significant association between risky sexual behavior and other sociodemographic variables such as educational status and income. While comparing the exposure to risky sexual behavior of respondents, second year were about three times exposed to risky sexual behavior than first year students and third year and above respondents were about five times exposed to risky sexual behavior than first year students with odds of $(\mathrm{AOR}=2.8,95 \% \mathrm{CI}=1,7.9)$ and $(\mathrm{AOR}=4.7,95 \% \mathrm{CI}=1.6$, 12.9) respectively. From ever use of substances only khat chewing was independently associated with risky sexual behavior with $(\mathrm{AOR}=2.5,95 \% \mathrm{CI}=1.1,7.9)$ (Table 4).

Table 4. Independent predictors of risky sexual behavior among bonga public college students, 2014.

\begin{tabular}{|c|c|c|c|c|c|}
\hline \multirow{3}{*}{ Variables } & \multirow{3}{*}{ Level } & \multicolumn{3}{|c|}{ Risky sexual behavior } & \multirow{3}{*}{$\operatorname{AOR}(95 \% \mathrm{CI})$} \\
\hline & & No & Yes & COR(95\%CI) & \\
\hline & & $\mathbf{N}(\%)$ & $\mathbf{N}(\%)$ & & \\
\hline \multirow{3}{*}{ Sex } & male & $50(73.5)$ & $53(63.9)$ & 1 & 1 \\
\hline & female & $18(26.5)$ & $30(36.1)$ & $1.5(0.8,3.1)$ & $4.5(1.7,12)^{*}$ \\
\hline & 1styear and level1 & $26(38.2)$ & $10(12.0)$ & 1 & 1 \\
\hline \multirow[t]{2}{*}{ Educational status } & 2ndyear and level 2 & $23(33.8)$ & $32(38.6)$ & $3.6(1.4,8.9)$ & $2.8(1,7.9)^{*}$ \\
\hline & 3rd year \& level 3- 4 & $19(27.9)$ & $41(49.4)$ & $5.6(2.2,13.9)$ & $4.7(1.6,12.9)^{*}$ \\
\hline \multirow[t]{2}{*}{ Income } & $100-299$ & $23(33.8)$ & $30(36.1)$ & $2.7(1.2,6.1)$ & $3.7(1.4,10)^{*}$ \\
\hline & $>=300$ & $11(16.2)$ & $38(45.8)$ & $7.6(3,18.8)$ & $13.7(4,42)^{*}$ \\
\hline \multirow{2}{*}{ Ever use of khat } & Yes & $11(16.2)$ & $28(33.7)$ & $2.6(1.2,5.8)$ & $2.5(1.1,6.5)^{*}$ \\
\hline & No & $57(83.8)$ & $55(66.3)$ & 1 & 1 \\
\hline
\end{tabular}

\section{Discussion}

Present study revealed the magnitude of risky sexual behaviors and the association between risky sexual behavior and substance use. The overall prevalence of "ever used substance" for at least one "substance" is $72.7 \%$. The most commonly used substances in descending order are: alcohol $(51.3 \%)$, khat $(15.4 \%)$, cigarette $(3.6 \%)$ and other illicit substances $(2.5 \%)$. This is higher than a similar study on Haromaya University students which was $53.8 \%$ but the sequence of used substances is similar [17].

In this study the current prevalence of khat chewing was found to be $11.4 \%$, which is lower than with study done among university students in North West Ethiopia, which was $17.5 \%$ and the study done among Hosanna Health Science College students which was $27.7 \%$ [16, 22]. The difference might be due to the availability of khat in the towns where these institutions are found.

The reasons given by the study participants for chewing khat were to increase academic (work) performance, to get personal pleasure, to stay awake and due to peer pressure. This is in line with other researches done in Haromaya University, Gondar University and Hosanna Health Science College. [13-14, 20]

The lifetime prevalence of khat chewing was $15.4 \%$. This result is lower than the result of study done on Haromaya university students which was $30.3 \%$ [13]. The possible reason for this discrepancy may be university students can get more income from families and relatives than college students.

The prevalence rate of lifetime alcohol use in this study was $51.3 \%$, which is higher than rate of lifetime alcohol use in Hosanna health science students which was 21.7\% [20] and lower than Nigerian students which was $61 \%$ [34]. The possible reason for this difference can be the income difference among Ethiopian and Nigerian families of the students. According to this study finding very few respondents $14(3.6 \%)$ only were using cigarette in their life time and $10(2.5 \%)$ had tried illicit drugs. This might be due to students didn't get these illicit drugs easily, and the possession and use of these drugs results in penalty under the 
law of the country.

In this study, $38.1 \%$ of the participating students admitted having sexual experience which accounts $38 \%$ for males and $38.4 \%$ for females. This result is higher with the study done in Haromaya university students which was $33.5 \%$ and the study on high school students in Dessie town which was $27.3 \%$ and lower than the study on Uganda university students which was $59 \%[13,17,36]$. The result difference is slight among studies conducted in Ethiopia and it is lower from the study conducted in Uganda. This might be due to the difference in cultures, attitudes and life style which lead students towards sexual debut.

While looking at unprotected sexual intercourse only $58.3 \%$ of respondents with sexual experience use condom always, $6.6 \%$ used condom inconsistently and the remaining $35.1 \%$ do not use condom. This is lower when compared to the study in China selected high school students which was $42.1 \%$ unprotected sexual intercourse (sexual intercourse without condom [(35].

The condom use rate during last intercourse among those sexually active students was $64.9 \%$, but consistent condom use was reported by $58.3 \%$. The result is consistent with similar study done among students of Haromaya university which was $55.7 \%$ [13].

In this study about $4.6 \%$ of sexually experienced participants have had sexual intercourse with two or more partners and this is very low when compared to the study in China selected high school students which was $49.4 \%$ and to the study on Jamaican adolescents which was $12 \%$ for females and $52 \%$ for males $[35,24]$.

Sex with commercial sex workers was reported by $4.6 \%$ of male students, which is lower than the study among high school students in northwest Ethiopia which was $11.9 \%$ and the study among Wolayta Sodo university students of $13.9 \%$ $(27,28)$. This might be due to the difference in cultures, attitudes and income status which lead male sexually experienced students towards commencing sex with commercial sex workers.

There was a significant and linear association between alcohol intake and risky sexual behavior with those using alcohol having about three times higher odds compared to those not using it. This might be due to the nature of alcohol in decreasing inhibitions, altering rational decision making and increasing risk taking behavior. This result is consistent with the study done among Haromaya university students which was $2.4[13,37]$. Use of khat was significantly associated with risky sexual activities. This result is similar to the findings of similar studies done in different setup [13, 31-37]. Studies showed that there is a strong association between khat chewing and alcohol consumption, and the combined use of both drugs had an amplifying effect on sexual risk behaviors that predispose to HIV and other STIs [13, 15]. The association between cigarette and illicit substance use and risky sexual behavior disappears in the bivariate and multivariate analysis. The relationship of risky sexual behavior and these substances use was strong in many literatures [8, 9, and 37]. But absence of relationship between these drugs use and sexual behavior in this study could be as a result of small sample size which leads to small number of users of these substances or under-reporting of the use of these substances by students because of cultural or legal issues. About $14 \%$ of sexually experienced respondents had seen genital symptoms of STIs and almost all did not go to health care center. This result is higher than the study conducted on Haromaya university students which were $4.1 \%$.

\section{Conclusions}

The prevalence of substance use among Bonga college students is high. Reasons forwarded for substance use from respondents include: to work/study hard from chewers and to get personal pleasure from drinkers. The study also showed that the majority of the students who were sexually active engaged in unsafe and risky sexual practices. Sex, year of study, income and ever use of khat were independently associated with risky sexual behavior.

\section{Authors Contributions}

AA, MS conceived of the study. AA, TG, HA and MS conducted the statistical analyses and interpretation. All authors wrote up the results and approved the final manuscript

\section{Acknowledgements}

Researchers want to thanks Jimma University for funding the research study, college administrative, study subjects and all authors read and approved the final manuscript.

\section{References}

[1] Ministry of Youth, Sports and Culture, National Youth Policy, Addis Ababa, Ethiopia 2004: p6, Govindasamy Pav, Aklilu Kidanu, and Hailom Bantayega,,Youth Reproductive Health in Ethiopia, Mizhasab Research Center, 2002, Addis Ababa, Ethiopia. Ministry of Health: Health and Health related indicators. Addis Ababa, Ethiopia 2006.

[2] WHO, UNAIDS, UNICEF. Global HIV AIDS Response Epidemic update and health sector progress towards Universal Access - Progress report 2011.Geneva, Switzerland. WHO, UNAIDS, UNICEF. Ministry of Health: Health and Health related indicators. Addis Ababa, Ethiopia 2008.

[3] Harvey, S. M. \& Beckman, L. J. Alcohol consumption, female sexual behavior and contraceptive use. Journal of Studieson Alcohol, 1986; 47 (4), 327--328.

[4] Dawit A, Asfaw D, Amare D: Khat chewing habit as a possible risk behavior for HIV infection. Ethiop J Health Dev 2005, 19(3):174-181.

[5] McKay, A. Sexuality and substance use: the impact of tobacco, alcohol, and selected recreational drugs on sexual function. The Canadian Journal of Human Sexuality, 2005; 14, 47-56. 
[6] Negussie Taffa, Sexual activity of out-of-school youth, and their knowledge and attitude about STDs and HIV/AIDs in Southern Ethiopia, Ethiopian Journal of Health Development, 1998, 12 (1):pp17-22, Addis Ababa, Ethiopia.

[7] Dawit A, Debela A, Dejene A, Abebe A, Mekonnen Y, Degefa A, et al. Is khat-chewingassociated with HIV risk behaviour? A community based study from Ethiopia. African Journal of AIDSResearch2006; 5(1):61-9.

[8] Fekadu M,Alemayehu W.Age at sexual initiation and factors associated with it among youths in North East Ethiopia. 2008

[9] Blum R. W and Mmari K. N. Risk and Protective Factors Affecting Adolescent Reproductive Health in Developing Countries; Geneva: World Health Organization.2005

[10] The Henry J. Kaiser Family Foundation: Substance Use and Risky Sexual Activity 2002

[11] Alice FY, Yu-Wen Chiu, Carolyn A, Min Qi Wang. STD/HIVRelated Sexual Risk Behaviors and Substance Use among U.S. Rural Adolescents; Journal of the National Medical Association 2007; 99(12):1386-94.

[12] Lori-Ann Palen eas,Linda L. CaldwelL CM, Vergnani AT. Transitions to Substance Use and Sexual Intercourse Among South African High School Students. 2009:1-16.

[13] Kebede Y. Cigarette smoking and Khat chewing among college students in North West Ethiopia. Ethiopian Journal of Health Development2002; 16(1):9-17.

[14] Derese A. Assessment of substance use and risky sexual behaviour among haramaya university students. Addis Ababa2011.

[15] Ibrahim N. Factors That Influences School Adolescents Exposure To HIV/STD In Bale, Oromia Region.2004:1-111.

[16] Hussien A. "FACTORS Promoting risky sexual behavior of high school adolescents in Dessie town, amhararegional state". 2008 1-90.

[17] Hibret Alemu1. Factors Predisposing Out-of-School Youths to HIV/AIDS-related Risky Sexual Behaviour in $\mathrm{N}$ orth west Ethiopia. 2007.

[18] Azazh. W. Substance use and its predictors among undergraduate medical students of Addis Ababa University in Ethiopia. BMC Public Health 2011:1-11.

[19] Angamo T. Substance use and sexual risk behavior and factors associated with HIV transmission in Southern Ethiopia. International Journal of Pharmaceutical Science and Research.2012(04):1-7.

[20] John-Lengba J, Ezeh A, Guiella G, Kumi-Kyereme A, Neema S. Alcohol, Drug Use, and Sexual-risk Behaviors among adolescents in four Sub-Saharan African countries. 2004.

[21] UNFPA Ethiopia. Preventing HIV/AIDS. 2007; Available from: http://countryoffice.unfpa.org/ethiopia/2008/12/30/278/preventi ng_hivaids/.
[22] Elizabeth W, Erin, Kristen $\mathrm{P}$ and Jennifer M Sexually Transmitted Diseases among Young Adults: Prevalence, Perceived Risk, and Risk-Taking Behaviors.2008:1-8.

[23] Kanako Ishida, and PS, McDonald O. Prevalence and Correlates of Sexual Risk Behaviors Among Jamaican Adolescents. 2011;37:1-10.

[24] (FHAPCO) FHAPaCO. Report on progress towards implementation of the UN Declaration of Commitment on HIV/AIDS. 2010.

[25] O'Hara1 RE. Greater Exposure to Sexual Content in Popular Movies Predicts Earlier Sexual Debut and Increased Sexual Risk Taking. 2012:1-15.

[26] Gashaw A, Afework K, Feleke M. Low prevalence of HIV infection, and knowledge, attitude and practice on HIV/AIDS among high school students in Gondar, Northwest Ethiopia. Ethiopian Journal of Health Development2007; 21(2):179-82.

[27] Bereket Y, Terefe G and Mulat T. Prevalence and Associated Factors of Sexually Transmitted Infections among Students of Wolaita Sodo University.2013: 1-9.

[28] Lewis ML, Lee, C. M., Patrick. M. E., Fossos, N. Genderspecific Normative Misperceptions of Risky Sexual Behavior and Alcohol-related Risky Sexual Behavior. 2007, 57, 81-90.

[29] UNFPA. (United Nations Population Fund), Global reach Indicators, Ethiopia, accessed.

[30] 2008 fromhttp://www.unfpa.org/profile/ethiopia.cfm.

[31] Graves K. Risky sexual behavior and alcohol use among young adults: Results from anational survey. American Journal of Health Promotion1995; 10.

[32] Kalina O, Gerckova MA, Jurcuska P, Orosova O, Van Dijk J, Reijneveld S. Psychological and behavioural factors associated with sexual risk behaviour among Slovak students. BMC Public Health2009; 9 (15).

[33] DeSimone. J Binge drinking and risky sex among college students Economics May2010.

[34] Cooper ML. Alcohol Use and Risky Sexual Behavior among College Students and Youth: Evaluating the Evidence. Department of Psychology, 210 McAlester Hall, University of Missouri-Columbia, Columbia, Missouri2002:1-17.

[35] Shenghui L, Hong H, Gang X, Yong C, Fengrong H and Xiuxia Y. Substance use, risky sexual behaviors, and their associations in a Chinese sample of senior high school students. BMC Public health 2013:1-10.

[36] Imaledo1 JA. Pattern of risky sexual behavior and associated factors among undergraduate students of the University of Port Harcourt, Rivers State, Nigeria. 2012:1-9.

[37] Kebede D, Alem A, Mitike G, Enquselassie F, Berhane F, Abebe Y, et al. Khat and alcohol use and riskysex behavior among in-school and out-of-school youth in Ethiopia. BMC Public Health 2005; 5:109. 